\title{
PERAN BADAN NARKOTIKA NASIONAL KABUPATEN KARAWANG DALAM PROGRAM (P4GN) BERDASARKAN INSTRUKSI PRESIDEN REPUBLIK INDONESIA NOMOR 6 TAHUN 2018 TENTANG RENCANA AKSI NASIONAL PENCEGAHAN DAN PEMBERANTASAN PENYALAHGUNAAN DAN PEREDARAN GELAP NARKOTIKA DAN PREKURSOR NARKOTIKA
}

\author{
Sartika Dewi, S.ST., M.H Email : sartikadewi@ubpkarawang.ac.id \\ Deny Guntara,S.H., M.H Email : deny.guntara@ubpkarawang.ac.id \\ Dicky Indrawan, S.H Email : dickyindrawan@mhs.ubpkarawang.ac.id
}

Fakultas Hukum Universitas Buana Perjuangan Karawang

\begin{abstract}
ABSTRAK
Penyalahgunaan narkotika sudah menjadi salah satu fenomena yang sangat meresahkan, terutama di kalangan remaja. Penyalahgunaan ini diatur dalam pasal 55 ayat (1) UndangUndang Nomor 35 Tahun 2009 Tentang Narkotika menegaskan bahwa untuk membantu pemerintah dalam menanggulanggi masalah dan bahaya penyalahgunaan Narkotika, penyalahgunaan dan peredaran gelap narkotika yang semakin tak terkendali membuat Badan Narkotika Nasional (BNN) membentuk Badan Narkotika Nasional Kabupaten, termasuk BNN Kabupaten Karawang. BNN Kabupaten Karawang mempunyai tugas, fungsi, dan wewenang yang sama dengan Badan Narkotika Nasional. Adapun permasalahan dalam penelitian ini tentang peran Badan Narkotika Nasional Kabupaten Karawang dalam mengimplementasikan program pencegahan dan pemberantasan penyalahgunaan dan peredaran gelap narkotika (P4GN) terhadap pelajar dan mahasiswa di Kabupaten Karawang, serta kendala-kendala yang di hadapi oleh Badan Narkotika Nasional Kabupaten Karawang terkait peran dalam mengimplementasikan program pencegahan dan pemberantasan penyalahgunaan dan peredaran gelap narkotika (P4GN). Metode Penelitian menggunakan pendekatan Yuridis Empiris karena data yang digunakan adalah data Primer yang diperoleh melalui studi lapangan dan wawancara. Adapun hasil dari penelitian ini adalah Badan Narkotika Nasional Kabupaten Karawang dalam implementasi program pencegahan pemberantasan penyalahgunaan dan peredaran gelap narkotika (P4GN) di Kabupaten Karawang, telah sesuai dengan Instruksi Presiden Nomor 6 Tahun 2018 Tentang Rencana Aksi Nasional pencegahan pemberantasan penyalahgunaan dan peredaran gelap narkotika dan Prekursor Narkotika walaupun belum maksimal. Dalam pelaksanannya tersebut masih terdapat beberapa hambatan yakni keterbatasan personil dan keterbatasan anggaran dan
\end{abstract}

Kata Kunci : Narkotika, BNN, P4GN 


\section{ABSTRACK}

Narcotics emphasizing that to assist the government in dealing with the problems and dangers of Narcotics abuse, narcotics abuse and illicit trafficking which are increasingly uncontrollable, the National Narcotics Agency (BNN) has formed a National Narcotics Agency National Narcotics District, including BNN Karawang Regency. Karawang Regency $B N N$ has the same duties, functions and authorities as the National Narcotics Agency. The problem in this research is about the role of the Karawang Regency National Narcotics Agency in implementing the program of prevention and eradication of narcotics abuse and illicit trafficking (P4GN) against students in the Karawang Regency, as well as the constraints faced by the Karawang Regency National Narcotics Agency related to the role in implement a program of prevention and eradication of narcotics abuse and illicit trafficking $(P 4 G N)$. This research method uses the Empirical Juridical approach because the data used are Primary data obtained through field studies and interviews. The results of this study are the National Narcotics Agency of Karawang Regency in implementing the prevention program to eradicate abuse and illicit narcotics trafficking (P4GN) in Karawang Regency, in accordance with Presidential Instruction Number 6 of 2018 concerning the National Action Plan to prevent the eradication of abuse and illicit narcotics and precursors. Narcotics, although not optimal. In the implementation, there are still several obstacles, namely limited personnel and budget constraints and the wide coverage area of supervision is not equal to the existing personnel of BNNK Karawang.

\section{Keyword : Narcotics, BNN, P4GN}


PERAN BADAN NARKOTIKA NASIONAL KABUPATEN KARAWANG DALAM PROGRAM (P4GN) BERDASARKAN INSTRUKSI PRESIDEN REPUBLIK INDONESIA NOMOR 6 TAHUN 2018 TENTANG RENCANA AKSI NASIONAL PENCEGAHAN DAN PEMBERANTASAN PENYALAHGUNAAN DAN PEREDARAN GELAP NARKOTIKA DAN PREKURSOR NARKOTIKA: Deny G., Sartika Dewi, Dicky I.

\section{PENDAHULUAN}

Candu yang kuat bagi penggunanya dan efek ketergantungan yang luar biasa. Ketergantungan yang dialami pemakai narkotika ini jika tidak terealisasi maka efek yang dialami adalah sakau, yaitu keadaan dimana orang tersebut mengalami rasa gelisah atau gangguan psikis atau psikologis akibat kecanduan putau. ${ }^{1}$

Dampak yang ditimbulkan karena pemakaian narkotika di atas, dapat diartikan bahwa penyalahgunaan narkotika adalah merupakan suatu tindak kejahatan dan pelanggaran yang mengancam keselamatan, baik fisik maupun jiwa si pemakai dan juga terhadap masyarakat disekitar secara sosial. 2

Pengaruh era globalisai yang ditandai dengan kemajuan teknologi komunikasi, liberalisasi perdagangan serta pesatnya kemajuan industri pariwisata menjadikan Indonesia semakin rawan terhadap peredaran gelap narkotika. Bahkan dewasa ini peredaran gelap narkotika di

\footnotetext{
${ }^{1}$ Heriady Willy, Berantas Narkotika Tak Cukup Hanya Bicara - (Tanya Jawaban dan Opini), Universitas Islam Indonesia, Yogyakarta, 2005, hlm.70.

${ }^{2}$ Makaraou. Moh. Taufik . Tindak Pidana Narkotika, Ghalia Indonesia, Jakarta, 2003, hlm.49
}

Indonesia semakin meningkat dengan dibuktikannya banyak kasus narkotika yang terjadi di Indonesia. Pemberitaan melalui media massa, baik media cetak maupun media elektronik, hampir setiap hari kita jumpai ada saja pemberitaan mengenai narkotika.

Peredaran gelap narkotika yang begitu cepat di Indonesia sebagai Negara berkembang di kawasan asia, tidak memandang status sosial seseorang dan tidak memilih siapa calon korbannya. Narkotika ini telah mempengaruhi dan merusak sendi kehidupan dalam lingkungan sosial di masyarakat Indonesia. Tidak sedikit orang menggunakan narkotika sebagai kebutuhan sehari-hari baik dari masyarakat lapisan atas, menengah atau masyarakat bawah sekalipun. Para pelaku dan korbannya tidak terbatas pada usia tertentu saja. Mulai dari yang tua sampai pada yang muda pun bisa jadi mangsa dari peredaran dan penyalahgunaan narkotika.

Permasalah penyalahgunaan dan peredaran gelap narkotika sangatlah kompleks hingga dalam permasalahan ini haruslah mempunyai suatu tatanan dan tindak hukum yang jelas dan tegas terhadap pengedar maupun pemakaiannya. Berdasarkan Undang-Undang Nomor 35 
PERAN BADAN NARKOTIKA NASIONAL KABUPATEN KARAWANG DALAM PROGRAM (P4GN) BERDASARKAN INSTRUKSI PRESIDEN REPUBLIK INDONESIA NOMOR 6 TAHUN 2018 TENTANG RENCANA AKSI NASIONAL PENCEGAHAN DAN PEMBERANTASAN PENYALAHGUNAAN DAN PEREDARAN GELAP NARKOTIKA DAN PREKURSOR NARKOTIKA: Deny G., Sartika Dewi, Dicky I.

Tahun 2009 Narkotika pada Pasal 112 ayat (1) atas perbuatan memiliki Narkotika golongan 1 dapat dipenjara paling singkat 4 (empat) tahun dan paling lama 12 (dua belas) tahun dan pidana paling sedikit Rp. 800.000.000.00 (Delapan ratus juta rupiah). Namun pada orang yang memiliki,menyimpan,menguasai,ataumenye diakan narkotika golongan 1 yang beratnya melebihi 5 (lima) gram, maka berdasarkan Pasal 112 ayat (2) Undang-Undang Narkotika, ancaman pidananya lebih berat, yaitu pidana penjara seumur hidup atau pidana penjara paling singkat 5 (lima) tahun dan paling lama 20 (dua puluh) tahun dan pidana denda maksimum sebagaimana disebutkan dalam Pasal 112 ayat (1) ditambah 1/3 (sepertiga).

Sebagai orang yang menggunakan narkotika tanpa hak atau melawan hukum, orang tesebut dapat dipidana berdasarkan Undang-Undang Nomor 35 Tahun 2009 Narkotika Pasal 127 ayat (1) huruf a yang mengatakan bahwa setiap penyalahgunaan narkotika golongan 1 bagi diri sendiri dipidanakan dengan pidana penjara paling lama 4 (empat) tahun. Jika penyalahgunaan tersebut dapat dibuktikan atau terbukti sebagai korban penyalahgunaan narkotika, penyalahguna tersebut wajib menjalani rehabilitasi medis dan rehabilitasi sosial Pasal 54.

Permasalahan penyalahgunaan dan peredaran gelap narkotika merupakan permasalahan yang masih dihadapi oleh Negara-negara di dunia, antara 153.300 juta jiwa atau sebesar $3,4 \% \quad-6,6 \%$ penyalahgunaan narkotika dunia usia 15-64 tahun pernah mengkonsumsi narkotika sekali dalam setahun, dimana hampir 12\% (15,5 juta jiwa sampai dengan 38,6 juta jiwa) dari pengguna adalah pecandu berat (World Drug Report, 2012).

Penyalahgunaan narkotika menduduki rangking ke-20 dunia sebagai penyebab angka kematian dan menduduki rangking ke-10 di Negara sedang berkembang termasuk Indonesia. Pada tahun 2010, prevalensi penyalahgunaan narkotika meningkat menjadi 2,21\% atau sekitar 4,02 juta orang. Pada tahun 2011,prevalensi penyalahgunaan meningkat menjadi 2,8\% atau sekitar 5 juta orang. ${ }^{3}$

Terkait dengan maraknya kasus narkotika di Indonesia berdasarkan data Survei Penyalahgunaan dan Peredaran Gelap Narkoba, Badan Narkotika Nasional pada tahun 2018 kelompok Pelajar dan

${ }^{3}$ World Drug Report,2013. 
PERAN BADAN NARKOTIKA NASIONAL KABUPATEN KARAWANG DALAM PROGRAM (P4GN) BERDASARKAN INSTRUKSI PRESIDEN REPUBLIK INDONESIA NOMOR 6 TAHUN 2018 TENTANG RENCANA AKSI NASIONAL PENCEGAHAN DAN PEMBERANTASAN PENYALAHGUNAAN DAN PEREDARAN GELAP NARKOTIKA DAN PREKURSOR NARKOTIKA: Deny G., Sartika Dewi, Dicky I.

Mahasiswa angka prevalensi penggunaan narkoba dikalangan Pelajar dan Mahasiswa sebesar 3,2\% atau setara dengan 2.297 .492 orang dari 5.440 .000 orang. ${ }^{4}$ Melihat prevalensi pengguna penyalahgunaan narkotika tersebut maka diperlukan perhatian khusus dan suatu langkah yang bijaksana dalam menangani permasalahan narkotika tersebut.

Selama ini Badan Narkotika Nasional Kabupaten Karawang dalam menanggulangi penyalahgunaan dan peredarana gelap narkotika tidaklah lepas dari upaya non penal dan upaya penal, upaya non penal (Pencegahan) yang dilakukan Badan Narkotika Nasional Kabupaten Karawang adalah melalui penyuluhan perundang-undangan tindak pidana bagi generasi muda yaitu pelajar dan mahasiswa se-Kabupaten Karawang. Terkait maraknya kasus narkotika di Karawang, yang dimana Provinsi Jawa Barat menempati peringkat ketiga pengguna penyalahgunaan narkotika wilayah Karawang. Berdasarkan data Badan Narkotika Nasional Kabupaten Karawang, pada tahun 2018 angka pengguna narkotika di Karawang menigkat dari tahun ke tahun,

4 Indonesia Drugs Report, 2019 Survei Penyalahgunaan dan Peredaran Gelap Narkoba Tahun 2018 (Kelompok Pelajar dan Mahasiswa), hlm.2 kondisi tersebut menempatkan Karawang di peringkat ke-3. Melihat prevalensi pengguna penyalahgunaan narkotika tersebut maka diperlukan perhatian khusus dan suatu langkah yang bijaksana dalam menangani permasalahan narkotika tersebut.

\section{PERMASALAHAN}

Berdasarkan latar belakang yang telah diuraikan diatas, maka dapat ditemukan beberapa masalah yang akan diteliti, yaitu :

1. Bagaimana peran Badan Narkotika Nasional Kabupaten Karawang dalam mengimplementasikan Program Pencegahan dan Pemberantasan Penyalahgunaan dan Peredaran Gelap Narkotika (P4GN di Kabupaten Karawang?

2. Apakah kendala yang mempengaruhi program Pencegahan dan Pemberantasan Penyalahgunaan dan Peredaran Gelap Narkotika (P4GN) yang dilakukan oleh

Badan Narkotika Nasional Kabupaten Karawang?

\section{METODE PENELITIAN}

Peneliti menggunakan metode pendekatan yuridis empiris yaitu pendekatan yang dilakukan dengan cara meneliti data 
PERAN BADAN NARKOTIKA NASIONAL KABUPATEN KARAWANG DALAM PROGRAM (P4GN) BERDASARKAN INSTRUKSI PRESIDEN REPUBLIK INDONESIA NOMOR 6 TAHUN 2018 TENTANG RENCANA AKSI NASIONAL PENCEGAHAN DAN PEMBERANTASAN PENYALAHGUNAAN DAN PEREDARAN GELAP NARKOTIKA DAN PREKURSOR NARKOTIKA: Deny G., Sartika Dewi, Dicky I.

primer yang diperoleh secara langsung ke lapangan dengan melihat secara implikasi dari peraturan perundang-undangan atau aturan hukum lain, serta dilakukan wawancara guna mengetahui kenyataan yang terjadi dalam prosedur penanganan dari beberapa responden yang dianggap dapat memberikan data dan informasi yang bener dan akurat. Analisis data yang dilakukan dalam penelitian ini yaitu menggunakan data kualititatif. Analisis data kualitatif artinya menguraikan data secara bermutu dalam bentuk kalimat yang teratur, runtun, logis tidak tumpang tindih dan efektif, sehingga memudahkan interpretasi data dan pemahaman hasil analisis. ${ }^{5}$

\section{PEMBAHASAN}

\section{A. Peran Badan Narkotika Nasional Kabupaten Karawang Dalam Mengimplementasikan Program (P4GN)}

Presiden Negara Indonesia menitik beratkan urgensi terhadap pencegahan peredaran gelap dan penyalahgunaan narkotika dan prekursor narkotika dengan mengeluarkan kebijakan yang baru yakni

\footnotetext{
5 Burhan Mustofa, Metode Penelitian Hukum, Rineka Cipta, Jakarta, 2004 hlm 24
}

Instruksi Presiden Republik Indonesia Nomor 6 Tahun 2018 Tentang Rencana Aksi Nasional Pencegahan dan Pemberantasan Penyalahgunaan Dan Peredaran Gelap Narkotika dan Prekursor Narkotika Tahun 2018-2019. Yang mana pada intinya kebijakan terebut merupakan suatu perintah secara tidak langsng terhadap beberpa instansi untuk melaksanakan aksi nasional dalam mencegah dan menindak penyalahgunaan dan peredaran gelap narkotika dan prekursor narkotika kepada beberpa instansi terkait yakni Para Menteri Kabinet Kerja, Sekertaris Kabinet, Jaksa Agung, Kepala Kepolisian Negara Republik Indoneia, Panglima Tentara Nasional Indonesia, Kepala Badan Intelejen Negara, Para Pimpinan Lembaga Pemerintah Non Kementrian, Para Pimpinan Kesekertariatan Lembaga Negara, Para Gubernur dan Para Bupati dan Walikota, serta tidak lepas pula terhadap seluruh masyarakat Indonesia dan seluruh element yang terlibat didalamnya. Penanggung jawab terhadap aksi tersebut dibebankan kepada instansi yang memiliki kewenangan penuh terhadap hal itu yakni Badan Narkotika Nasional. Dalam menjalankan tugas dan fungsinya, tentunya disesuaikan dengan hierarki kelembagaan dari Badan Narkotika Nasional yakni Badan 
PERAN BADAN NARKOTIKA NASIONAL KABUPATEN KARAWANG DALAM PROGRAM (P4GN) BERDASARKAN INSTRUKSI PRESIDEN REPUBLIK INDONESIA NOMOR 6 TAHUN 2018 TENTANG RENCANA AKSI NASIONAL PENCEGAHAN DAN PEMBERANTASAN PENYALAHGUNAAN DAN PEREDARAN GELAP NARKOTIKA DAN PREKURSOR NARKOTIKA: Deny G., Sartika Dewi, Dicky I.

Narkotika Nasional Republik Indonesia, Badan Narkotika Nasional Provinsi (BNNP) dan Badan Narkotika Nasional Kabupaten/Kota (BNNK).

Termasuk salah satunya adalah Badan Narkotika Nasional Kabupaten Karawang. Dalam hal menjalankan tugas dan fungsinya berdasarakan lembaran lampiran dari Instruksi Presiden Republik Indonesia Nomor 6 Tahun 2008 tentang Rencana Aksi Nasional Pencegahan dan Peberantasan Peredaran dan Penyalahgunaan Narkotika dan Prekursor Narkotika di Kabupaten Karawang, dijalankan sesuai dengan bidangnya masing-masing. Dalam hal ini, BNN Kabupaten Karawang membagi tugas dan fungsinya menjadi 3 (tiga) bagian yang dijalankan oleh 3 (tiga) seksi yaitu seksi Pencegahan dan Pemberdasayaan Masyarakat, Seksi Pemberantasan dan Seksi Rehabilitasi. Adapun terkait dengan reaslisasi tugas dan fungsinya dalam menjalankan Instruksi Presiden Republik Indonesia Nomor 6 Tahun 2008 tentang Rencana Aksi Nasional Pencegahan dan Peberantasan Peredaran dan Penyalahgunaan Narkotika dan Prekursor Narkotika di Kabupaten Karawang di masing-masing seksi adalah sebagai berikut :

\section{Seksi Pencegahan Dan Pemberdayaan Masyarakat}

Bidang Pencegahan dan Bidang Pemberdayaan Masayarakat di dalam organisasi Badan Narkotika Nasional Kabupaten Karawang merupakan satu kesatuan tugas dan fungsi yang berbeda yang dilaksanakan oleh satu seksi, yakni Seksi Pencegahan dan Pemberdayaan Masyarakat. Hal ini didasarkan pada Pasal 27 Ayat (1)dan Ayat (2) Peraturan Kepala Badan Narkotika Nasional Nomor PER/4/V/2010/BNN Tentang Organisasi Dan Tata Kerja Badan Narkotika Nasional Provinsi Dan Badan Narkotika Nasional Kabupaten/Kota menyatakan bahwa Seksi Pencegahan mempunyai tugas melakukan penyiapan pelaksanaan kebijakan teknis P4GN di bidang pencegahan dalam wilayah Kabupaten/Kota. Sementara itu Seksi Pencegahan Pemberdayaan Masyarakat mempunyai tugas melakukan penyiapan pelaksanaan kebijakan teknis P4GN di bidang pemberdayaan masyarakat dan rehabilitasi dalam wilayah Kabupaten/Kota.

Pelaksanaan tugas pokok dan fungsi tersebut dilaksanakan melalui :

\section{a. Desiminasi Informasi}


PERAN BADAN NARKOTIKA NASIONAL KABUPATEN KARAWANG DALAM PROGRAM (P4GN) BERDASARKAN INSTRUKSI PRESIDEN REPUBLIK INDONESIA NOMOR 6 TAHUN 2018 TENTANG RENCANA AKSI NASIONAL PENCEGAHAN DAN PEMBERANTASAN PENYALAHGUNAAN DAN PEREDARAN GELAP NARKOTIKA DAN PREKURSOR NARKOTIKA: Deny G., Sartika Dewi, Dicky I.

Desiminasi informasi ini adalah suatu kegiatan yang dilakukan oleh BNNK Karawang dengan tujuan agar target atau sasaran dari kegiatan ini dapat memperoleh informasi, menimbulkan kesadaran, menerima dan memanfaatkan informasi yang disampaikan terkait dengan dampak dari penyelahgunaan serta pengedaran Narkotika secara gelap. Kegiatan ini merupakan kegiatan penyuluhan ataupun sebagai media yang konvensional yang dilakukan BNNK Karawang baik secara tatap muka, maupun melalui media cetak, media elektronik dan internet dalam hal penyampaian informasi tersebut. Bukan hanya itu, kegiatan ini, dilakukan dengan berbagai cara seperti hal nya pembuatan dan penyebaran pamflet ataupun stiker, baliho dan banner yang bertuliskan dan berisikan pesan terhadap bahaya Narkotika seperti "Stop Penggunaan Narkoba, Katakan Tidak Pada Narkoba, Prestasi yes Narkoba No" yang disertakan pula dengan pusat pesan atau pusat informasi dari BNNK Karawang tentunya hal tersebut dilakukan di wilayah hukum Kabupaten Karawang yang tersebar ke beberapa Kecamatan.

Kegiatan desiminasi informasi melalui penyuluhan dilakukan oleh BNNK Karawang tentang bahaya narkoba, dengan tujuan untuk supaya secara sadar dan berencana yang dilakukan untuk memperbaiki perilaku manusia, sesuai dengan prinsip-prinsip pendidikan, yakni pada tingkat sebelum seseorang menggunakan narkoba, agar mampu menghindar dari penyalahgunaannya. Upaya ini diharapkan efektif karena ditunjukan pada mereka yang belum pernah menggunakan atau sudah menggunakan pada tingkat coba-coba. ${ }^{6}$

Upaya Pencegahan dalam bentuk sosialisasi bahaya narkoba tersebut pada tahun 2018 dan 2019 telah dilaksanakan di beberpa instansi baik ditingkat Sekolah Dasar, Sekolah Mengah Pertama, Sekolah menangah Atas maupun di Perguruan Tinggi yang berada di Kabupaten Karawang.

Dari hasil wawancara dengan pihak BNNK Karawang ${ }^{7}$ terkait dengan hasil pelaksanaan kegiatan diseminasi informasi pencegahan dan pemberantasan penyalahgunaan dan peredaran gelap narkoba (P4GN) di lingkungan sekolah dimana dalam kegiatan ini mampu

6 Hari Sasangka, Narkotika dan Psikotropika dalam Hukum Pidana, Mandar Maju, Bandung, 2003.

\footnotetext{
${ }^{7}$ Hasil wawancara dengan bu anggita koord sek P4GN mei 2021
} 
PERAN BADAN NARKOTIKA NASIONAL KABUPATEN KARAWANG DALAM PROGRAM (P4GN) BERDASARKAN INSTRUKSI PRESIDEN REPUBLIK INDONESIA NOMOR 6 TAHUN 2018 TENTANG RENCANA AKSI NASIONAL PENCEGAHAN DAN PEMBERANTASAN PENYALAHGUNAAN DAN PEREDARAN GELAP NARKOTIKA DAN PREKURSOR NARKOTIKA: Deny G., Sartika Dewi, Dicky I.

mengurangi penyalahgunaan dan peredaran gelap di sekolah-sekolah yang ada di Kabupaten Karawang. Keberhasilan kegiatan ini tidak lepas dari sikap kooperatif dari sekolah terkait untuk bekerjasama dengan Badan Narkotika Nasional Kabupaten Karawang untuk mengawasi dan menjaga siswa di lingkungan sekolah agar terhindar dari bahaya penyalahgunaan dan peredaran gelap narkoba yang bertujuan untuk menciptakan lingkungan bebas narkoba.

Selain di lingkungan pendidikan, sosialisasi atau desiminasi penyuluhan inipun dilakukan oleh BNNK Karawang dengan sasaran adalah Lingkungan Pemerintahan dan Swasta. Program kegiatan diseminasi informasi pencegahan dan pemberantasan penyalahgunaan dan peredaran gelap narkoba (P4GN) di lingkungan pemerintahan/swasta merupakan program kegiatan Badan Narkotika Nasional Kabupaten Karawang yang termasuk pula di dalam Rencana Aksi Nasional 2018 di bidang pencegahan oleh seksi Pencegahan dan Pemberdayaan Masyarakat BNNK Karawang yang dimana program kegiatan ini mempunyai sasaran strategis yakni meningkatnya pengetahuan, pemahaman, dan kesadaran pekerja terhadap bahaya penyalahgunaan dan peredaran gelap Narkotika.

Berdasarkan hasil pelaksanaan kegiatan diseminasi informasi pencegahan dan pemberantasan penyalahgunaan dan peredaran gelap narkoba (P4GN) di lingkungan pemerintahan dan swasta yang mana dalam program kegiatan ini diharapkan mampu mengurangi penyalahgunaan dan peredaran gelap narkotika dilingkungan kerjanya tersebut. Keberhasilan kegiatan ini tidak lepas dari sikap kooperatif dari lingkungan kerja terkait untuk bekerjasama dengan Badan Nasional Narkotika Kabupaten Karawang dalam mengawasi para pekerja yang ada di lingkungan kerja pemerintahan dataupun swasta agar dapat terhindar dari bahaya penyalahgunaan dan peredaran gelap narkoba yang bertujuan untuk menciptakan lingkungan bebas narkoba. ${ }^{8}$

\section{b. Pemberdayaan \\ Masyarakat Melalui Tes Urine}

Pelaksanaan tes urin secara berkala yang dilakukan oleh seksi Pencegahan dan

\footnotetext{
${ }^{8}$ Sholehuddin, M., Sistem Sanksi Dalam Hukum Pidana Ide Dasar Double track System dan Implementasinya, Raja Grafindo persada, Jakarta, 2003 hlm 78
} 
PERAN BADAN NARKOTIKA NASIONAL KABUPATEN KARAWANG DALAM PROGRAM (P4GN) BERDASARKAN INSTRUKSI PRESIDEN REPUBLIK INDONESIA NOMOR 6 TAHUN 2018 TENTANG RENCANA AKSI NASIONAL PENCEGAHAN DAN PEMBERANTASAN PENYALAHGUNAAN DAN PEREDARAN GELAP NARKOTIKA DAN PREKURSOR NARKOTIKA: Deny G., Sartika Dewi, Dicky I.

Pemberdayaan Masyarakat Badan Narkotika

Nasional Kabupaten Karawang adalah merupakan salah satu kegiatan dalam upaya pencegahan peredaran dan penyalahgunaan narkotika. Hal tersebut dilakukan terhadap masayarakat dengan zonasi rawan peredaran gelap dan penyalahgunaan narkotika di lingkungan Kabupaten Karawang.

\section{c. Iklan Layanan Media Cetak}

Dengan iklan layanan melalui media cetak dan kelembagaan merupakan salah satu strategi yang dimiliki Badan Narkotika Nasional Kabupaten Karawang dalam mendukung upaya pencegahan dan pemberantasan penyalahgunaan dan peredaran gelap narkoba $(\mathrm{P} 4 \mathrm{GN})$. Untuk saat ini Badan Narkotika Nasional sendiri sudah melakukan upaya memanfaatkan media iklan layanan dalam surat kabar seperti Koran Harian TV Berita, Fakta Jabar, Radar Karawang dan media yang lainnya.hasil dari pelaksanaan Iklan layanan melalui media cetak dan kelembagaan dapat dikatakan belum maksimal dikarenakan kegiatan tersebut belum mampu menyentuh seluruh kalangan masyarakat di Kabupaten Karawang dikarenakan pendistribusian Surat Kabar tersebut yang jumlahnya terbatas.

\section{d. Iklan P4GN Melalui Baliho dan Banner}

Iklan pencegahan dan pemberantasan penyalahgunaan dan peredaran gelap narkoba (P4GN) melalui baliho dan banner merupakan salah satu bentuk strategi yang dilakukan oleh Badan Narkotika Nasional Kabupaten Karawang. pemasangan iklan melalui baliho tersebut adalah untuk mendukung kegiatan Badan Narkotika Nasional Kabupaten Karawang. yang berkaitan dengan P4GN baik berupa peringatan, ajakan atau seruan agar tidak terjerumus kedalam penyalahgunaan narkoba. Hanya saja jumlahnya yang terbatas membuat manfaat dari iklan P4GN melalui baliho tersebut tidak dapat mencakup seluruh masyarakat, dikarenakan baliho seperti ini hanya tersedia di jalanan umum di Kabupaten Karawang dan tidak seluruhnya lingkungan Masyarakat Desa di Kabupaten Karawang mendapatkan media ini. Hal tersebut juga terkait dengan anggaran yang dikeluarkan belum bisa mencukupi untuk pengadaan media tersebut.

Berdasarkan hasil dari pelaksanaan iklan P4GN melalui baliho, program kegiatan ini telah diadakan di beberapa tempat dan terbukti bahwa dengan adanya 
PERAN BADAN NARKOTIKA NASIONAL KABUPATEN KARAWANG DALAM PROGRAM (P4GN) BERDASARKAN INSTRUKSI PRESIDEN REPUBLIK INDONESIA NOMOR 6 TAHUN 2018 TENTANG RENCANA AKSI NASIONAL PENCEGAHAN DAN PEMBERANTASAN PENYALAHGUNAAN DAN PEREDARAN GELAP NARKOTIKA DAN PREKURSOR NARKOTIKA: Deny G., Sartika Dewi, Dicky I.

baliho tersebut warga masyarakat sekitar menjadi lebih antusias menjaga lingkungan wilayahnya dari penyalahgunaan dan peredaran narkoba dan untuk saat ini di beberapa wilayah tersebut belum ditemukan laporan-laporan kasus-kasus penyalahgunaan narkoba.

\section{Seksi Rehabilitasi}

Berdasarkan Pasal 54 Undang-Undang No 35 Tahun 2009 tentang Narkotika menentukan bahwa Pecandu Narkotika dan korban penyalahgunaan narkotika wajib menjalani Rehabilitasi medis dan Rehabilitasi sosial. Yang dimaksud dengan Korban penyalahgunaan narkotika adalah seseorang yang tidak sengaja menggunakan narkotika karena dibujuk, diperdaya, ditipu, dipaksa, dan / atau diancam untuk menggunakan narkotika. Sehingga mereka diwajibkan mendapatkan rehabilitasi baik medis maupun sosial. Implementasi dalam pasal tersbeut diatas adalah, yakni mewajibkan rehabilitasi yang diperuntukan terhadap pecandu dari penyalahgunaan narkotika yang ketergantungan dengan narkotika terutama golongan I, sehingga ada upaya oleh BNN bagi para pecandu guna mendapatkan rehabilitasi medis dan rehabilitasi sosial dengan tujuan dapat memulihkan serta mengembalikan pecandu agar bisa berada dalam lingkungan masyarakat secara normal dan terbebas dari ketergantungan bahaya narkotika.

Kemudian dengan turunnya Peraturan Pemerintah Nomor 25 tahun 2011 Tentang Wajib Lapor Bagi Penyalahguna Narkotika, merupakan wujud komitmen negara untuk mengakomodir hak pecandu dalam mendapatkan layanan terapi dan rehabililtasi dan juga sebagai wujud implementasi dari pada Pasal 54 Undang-undang Nomor 35 Tahun 2009 tentang Narkotika. Dengan adanya upaya rehabilitasi oleh $\mathrm{BNN}$ Kabupaten Karawang diharapkan dapat memulihkan serta mengembalikan pecandu agar bisa berada dalam lingkungan masyarakat secara normal dan terbebas dari ketergantungan bahaya narkotika dan yang paling penting agar pecandu tidak kembali menyalahgunakan narkotika atau Relapse. Rehabilitasi sebagai tujuan utama dari jenis sanksi/treatment, meski cara ini memiliki keistimewaaan dari segi proses sosialisasi pelaku sehinga diharapkan mampu memulihkan kualitas sosial dan moral 
PERAN BADAN NARKOTIKA NASIONAL KABUPATEN KARAWANG DALAM PROGRAM (P4GN) BERDASARKAN INSTRUKSI PRESIDEN REPUBLIK INDONESIA NOMOR 6 TAHUN 2018 TENTANG RENCANA AKSI NASIONAL PENCEGAHAN DAN PEMBERANTASAN PENYALAHGUNAAN DAN PEREDARAN GELAP NARKOTIKA DAN PREKURSOR NARKOTIKA: Deny G., Sartika Dewi, Dicky I.

seseorang agar dapat berintegritas lagi dalam masyarakat. ${ }^{9}$

Dari pernyataan tersebut, Badan Narkotika Nasional Kabupaten Karawang secara konsisten melaksanakan fungsinya dalam kegiatan rehabilitasi. Berikut adalah data yang didapatkan oleh penulis terkait dengan pengguna narkotika yang di rehabilitasi pada tahun 2018 BNNK Kabupetan Karawang merehabilitasi dengan metode rawat jalan terhadap penyalahguna dengan kategori ringan 30 (tiga puluh) orang dan kategori berat adalah 44 (empat puluh empat) orang, zat utama yang disalah gunakan adalah Tramadol, Sedatif/Benzo, Amfetamin dan Kanabis. Sementara itu peningkatan jumlah penyalahguna yang direhabilitasi pada tahun 2019. Tercatat secara rinci perawaatan dilakukan di berbagai tempat yaitu rumah sakit ataupun klinik dan puskesmas, terhadap pasien penyalahguna dengan kategori ringan adalah sebanyak 29 (dua puluh Sembilan) orang, kategori sedang adalah sebanyak 35 (tiga puluh lima) orang, dan kategori berat adalah 1 (satu) orang. Masing-masing telah menyalahgunakan zat-zat

9 Makaraou. Moh. Taufik, Tindak Pidana Narkotika, Jakarta : Ghalia Indonesia. 2003 hlm 21
Tramadol,Sedatif/Bnzo,Amfetamin dan Kanabis. ${ }^{10}$

\section{Seksi Pemberantasan}

Berdasarkan Pasal 27 Ayat

Peraturan Kepala Badan Narkotika Nasional Nomor Per/4/V/2010/BNN Tentang Organisasi Dan Tata Kerja Badan Narkotika Nasional Provinsi Dan Badan Narkotika Nasional Kabupaten/Kota menyatakan bahwa Seksi Pemberantasan mempunyai tugas melakukan penyiapan pelaksanaan kebijakan teknis P4GN di bidang pemberantasan dalam rangka pemetaan jaringan kejahatan terorganisasi penyalahgunaan dan peredaran gelap narkotika, psikotropika, prekursor, dan bahan adiktif lainnya kecuali bahan adiktif untuk tembakau dan alkohol dalam wilayah Kabupaten/Kota.

Seksi Pemberantasan di BNNK Karawang dalam melakukan tugasnya terhadap pencegahan dan pemberantasan penyalahgunaan dan peredaran gelap narkotika adalah dengan lebih dahulu melakukan suatu Pemetaan Jaringan di Tempat/Lokasi Rawan Narkoba merupakan salah satu usaha yang dilakukan Badan

10 F Asya, Narkotika dan Psikotropika, Asa Mandiri, Jakarta, 2009. HIm 88 
PERAN BADAN NARKOTIKA NASIONAL KABUPATEN KARAWANG DALAM PROGRAM (P4GN) BERDASARKAN INSTRUKSI PRESIDEN REPUBLIK INDONESIA NOMOR 6 TAHUN 2018 TENTANG RENCANA AKSI NASIONAL PENCEGAHAN DAN PEMBERANTASAN PENYALAHGUNAAN DAN PEREDARAN GELAP NARKOTIKA DAN PREKURSOR NARKOTIKA: Deny G., Sartika Dewi, Dicky I.

Narkotika Nasional Kabupaten Karawang dalam bidang Pemberantasan. Kegiatan ini dilakukan dengan cara bekerja sama baik dengan tokoh masyarakat, warga sekitar maupun stakeholder lainnya dalam mencari dan memperoleh informasi penyalahgunaan dan peredaran gelap narkoba pada tempat/lokasi rawan narkoba yang ada di Kabupaten Karawang Informasi yang didapat dan dikumpulkan selanjutnya akan di analisis kembali oleh Badan Narkotika Nasional Kabupaten Karawang agar dapat memperoleh data yang akurat. Dalam melakukan tugas pemberantasan penyalahgunaan dan peredaran gelap narkotika dan presekusor narkotika, BNN berwenang melakukan penyelidikan dan penyidikan penyalahgunaan dan peredaran gelap narkotika dan presekusor narkotika. ${ }^{11}$ Hal ini disampaikan pula oleh kepala seksi pemberantasan BNNK Karawang yakni Bapak Gunadi dalam sosialisasi P4GN kepada masayarakat bahwa, penindakan untuk dilakukan penyidikan dan penyelidikan bersama aparat terkait yakni kepolisian adalah sebelumnya berdasarkan laporan masyarakat terhadap adanya dugaan

11 Hari Sasangka, Narkotika dan Psikotropika dalam Hukum Pidana, Mandar Maju, Bandung, 2003. Hlm 15 penyalahgunaan dan peredaran gelap narkotika dan prekursor narkotika di Kabupaten Karawang. Setelah menerima laporan, pihak $\mathrm{BNN}$ melalui bidang pemberantasan mengkaji dan mengobservasi terhadap target operasi dari pemberantasan ini. Setelah selesai, baru lah kemudian peredaran gelap narkotika dan penyalagunaan narkotika, melalui seksi pemberantasan diekseskusi untuk dilakukan penyelidikan dan penyidikan bersama kepolisian. $^{12}$

\section{B. Kendala Yang Mempengaruhi Program (P4GN)}

Proses pelaksanaan dan implementasi Instruksi Presiden Nomor 6 tahun 2018 tentang Rencana Akasi Nasional Pencegahan dan Pemberantasan Penyalahgunaan dan Peredaran Gelap Narkotika Dan Prekursor Narkotika oleh Badan Narkotika Nasional Kabuaten Karawang, sebagian besar sudah sesuai denga apa yang menjadi tugas dan fungsinya berdasarkan peraturan a quo dan dapat dikatakan sudah cukup baik. Namun dalam pelaksanaanya tersebut, bukan suatu hal yang mudah dan dapat berjalan dengan

12 Yusuf Apandi, Katakan tidak pada narkoba, Simbiosa Rekatama Mebia, Bandung, 2010 hlm36 
PERAN BADAN NARKOTIKA NASIONAL KABUPATEN KARAWANG DALAM PROGRAM (P4GN) BERDASARKAN INSTRUKSI PRESIDEN REPUBLIK INDONESIA NOMOR 6 TAHUN 2018 TENTANG RENCANA AKSI NASIONAL PENCEGAHAN DAN PEMBERANTASAN PENYALAHGUNAAN DAN PEREDARAN GELAP NARKOTIKA DAN PREKURSOR NARKOTIKA: Deny G., Sartika Dewi, Dicky I.

lancar sesuai dengan apa yang sudah direncanakan. Dalam hal ini, masih terdapat beberapa kendala terkait yang dihadapi oleh BNNK Karawang dalam proses realisasi program-program pemerintah tersebut dalam Pencegahan Pemberantasan Penyalahgunaan dan Peredaran Gelap Narkotika dan Prekursor Narkotika. ${ }^{13}$ Adapun beberapa kendala dan atau hambatan yang dihadapi BNNK Karawang berdasarkan hasil wawancara secara langsung, penulis membagi kedalam 2 (dua) kategori yaitu hambatan internal dan hambatan eksternal. Yang mana adalah sebagai berikut :

1. Hambatan Internal BNN Kabupaten Karawang

\section{a. Personil BNN Kabupaten Karawang Yang Terbatas}

Personil yang terbatas menjadi suatu kendala Badan Narkotika Nasional Kabupaten Karawang dalam menjalankan tugas Pencegahan Pemberantasan Penyalahgunaan dan Peredaran Gelap Narkotika, hal ini terkait dengan usia pembentukan BNNK Karawang yang

\footnotetext{
${ }^{13}$ William Banton, Ensiklopedia Bronotica, USA 1970, Volume 16. Lihat juga: Mardani, Penyalahgunaan Narkoba: dalam perspektif Hukum Islam dan Pidana Nasional, Jakarta : Rajawali press. 2008.
}

tergolong masih sangat muda yakni dibentuk dan berdiri dari 01 Januari 2012 dan mulai efektif pada Tahun 2017. Hal tersebut terkait degan berbagai hal sehingga 2017 BNNK Karawang dapat berjalan dengan efektif, walaupun status kantor BNNK Karawang yang belum tetap. Untuk saat ini Personil BNNK Kabupaten Karawang berjumlah 19 orang personil yang diantaranya adalah 1 orang kepala BNNK, 1 orang Kasubag Umum, 6 orang seksi pencegahan dan pemberdayaan masayarakat, 5 orang seksi rehabilitasi, dan 6 orang adalah sesksi pemberantasan.

\section{b. Anggaran Yang Terbatas}

Badan Narkotika Nasional Kabupaten Karawang dalam melaksanakan tugas dan fungsinya untuk merealisasikan Program P4GN ini, sudah tentu harus memiliki anggaran yang tidak sedikit atau dalam hal ini adalah cukup besar. Namun anggaran yang diterima oleh BNNK Karawang masih belum cukup untuk merealisasikan Program Pencegahan Pemberantasan Penyalahgunaan dan Peredaran Gelap Narkotika, dalam anggaran yang diterima sebenarnya sudah di tentukan sesuai porsi masing-masing seksi, misalnya dalam melaksanakan program Penyuluhan 
PERAN BADAN NARKOTIKA NASIONAL KABUPATEN KARAWANG DALAM PROGRAM (P4GN) BERDASARKAN INSTRUKSI PRESIDEN REPUBLIK INDONESIA NOMOR 6 TAHUN 2018 TENTANG RENCANA AKSI NASIONAL PENCEGAHAN DAN PEMBERANTASAN PENYALAHGUNAAN DAN PEREDARAN GELAP NARKOTIKA DAN PREKURSOR NARKOTIKA: Deny G., Sartika Dewi, Dicky I.

dari seksi Pencegahan dan Pemberantasan memiliki anggaran untuk kuantitas penyuluhan 100 kali dalam satu tahun namun untuk kondisi wilayah Kabupaten Karawang sendiri yang cukup luas tentunya tidak bisa dilaksanakan hanya untuk kuantitas sebanyak 100 kali untuk cakupan luasnya wilayah Kabupaten Karawang yang terbagi kedalam 33 Kecamatan tersebut.

\section{c. Wilayah Pemantauan dan Pengawasan Yang Luas}

Pembentukan dan pendirian Badan Narkotika Nasional Kabupaten Karawang yang berada di pusat Kabupaten Karawang, dan menjadi satu-satunya badan yang bertindak sebagai otoritas terkait dengan penyalahgunaan dan peredaran gelap narkotika, menjadi salah satu kendala terbatasanya proses pemantauan secara langsung daerah-daerah kecamatan yang berada di wilayah Kabupaten Karawang yang begitu luas yang dihubungakn pula dengan banyaknya populasi penduduk Kabupaten Karawang yang semakin tahun semakin meningkat. selanjutnya adalah semakin dengan semakin banyaknya populasi penduduk Kabupaten Karawang, ini menandakan pula semakin luas pula wilayah pantau BNNK Karawang terhadap pelaku penyalahgunaan dan peredaran gelap narkotika. Terutama wilayah-wilayah pesisir dan wilayah yang rawan akan penyalahgunaan dan peredaran narkotika seperti Klari, Cikampek, Tempuran, Karawang Barat, Karawang Timur, Banyusari, Telukjambe Barat, Majalaya, dan Telagasari. Wialayah pantau yang sangat luas dan populasi penduduk yang dari tahun ke tahun semakin meningkat serta di hubungkan dengan jumlah personil BNNK Karawang yang terbatas, ini menjadi salah satu kendala dalam upaya merealisasikan Program Pencegahan Pemberantasan Penyalahgunaan dan Peredaran Gelap Narkotika di Kabupaten Karawang. Terkait dengan kendala tersebut, diharapkan BNNK Karawang dapat mengakomodir secara maksimal dalam menjalankan tugas dan fungsinya sesuai dengan apa yang menjadi tujuan dari impelementasi Instruksi Presiden Nomor 6 tahun 2018 tentang Rencana Akasi Nasional Pencegahan dan Pemberantasan Penyalahgunaan dan Peredaran Gelap Narkotika Dan Prekursor Narkotika.

\section{d. Media Teknologi Deteksi Dini Narkotika Belum} Tersedia 
PERAN BADAN NARKOTIKA NASIONAL KABUPATEN KARAWANG DALAM PROGRAM (P4GN) BERDASARKAN INSTRUKSI PRESIDEN REPUBLIK INDONESIA NOMOR 6 TAHUN 2018 TENTANG RENCANA AKSI NASIONAL PENCEGAHAN DAN PEMBERANTASAN PENYALAHGUNAAN DAN PEREDARAN GELAP NARKOTIKA DAN PREKURSOR NARKOTIKA: Deny G., Sartika Dewi, Dicky I.

Belum tersedianya alat yang canggih merupakan salah satu hambatan bagi BNN Kabupaten Karawang dalam menjalankan tugas dan fungsinya yang bekerja secara otomatis untuk mendeteksi narkotika masuk yang memanfaatkan pintu lalu lintas keluar masuknya orang dari dalam maupun luar Kabupaten Karawang, atau yang tersedia di setiap perbatasan daerah Kabupaten Karawang. Selama ini, BNNK Karawang dalam melaksanakan pendeteksian narkotika dibantu oleh aparatur kepolisian menggunakan media anjing pelacak yang masih belum dapat efektif hingga saat ini.

\section{Hambatan Eksternal BNN Kabupaten Karawang}

Berdasarkan dari hasil wawancara yang dilakukan oleh penulis terhadap salah satu personil BNN Kabupaten Karawang yakni Kasubag Bagian Umum BNN Kabupaten Karawang terkait dengan kendala yang menjadi hambatan yang berasal dari luar BNN Kabupaten Karawang sendiri menjelaskan bahwa hingga saat ini dalam menjalankan tugas dan fungsinya, $\mathrm{BNN}$ Kabupaten karawang belum menemui hambatan atau kendala yang temui dan dialami. Dalam menjalankan tugasnya untuk merealisasikan program Pencegahan
Pemberantasan Penyalahgunaan dan Peredaran Gelap Narkotika dan Prekursor Narkotika, pihak BNN Kabupaten Karawang justru selalu mendapatkan respon yang baik dari berbagai instansi maupun element masyarakat lainnya, yang menjadi sasaran pencegahan penyalahgunaan dan peredaran gelap narkotika dan prekursor narkotika. Bukan hanya itu, komunikasi dan koordinasi yang dijalin dengan berbagai instansi dan atau lembaga lainnya, dan masyarakat di Lingkungan Kabupaten Karawang masih berjalan dan terjalin dengan baik. kondisi demikian pula terjalin dengan baik antara BNN Kabupaten Karawang, BNN Provinsi Jawa BArat dan tentunya BNN Pusat.

Upaya penanggulangan terhadap penyalahgunaan dan Peredaran Gelap narkotika dan Prekursor Narkotika yang dilakukan oleh BNN Kabupaten Karawang, bukan hanya dilakukan secara pidana, melainkan pula dengan beberapa upayaupaya yang lain yang berorientasi pada strategi sesuai dengan yang tertuang dalan lampiran Instruksi Presiden Nomor 6 Tahun 2018 tentang Rencana Aksi Nasional Pencegahan Pemberantasan Penyalahgunaan dan Peredaran Gelap Narkotika dan Prekursor Narkotika. Upaya-upaya tersebut 
PERAN BADAN NARKOTIKA NASIONAL KABUPATEN KARAWANG DALAM PROGRAM (P4GN) BERDASARKAN INSTRUKSI PRESIDEN REPUBLIK INDONESIA NOMOR 6 TAHUN 2018 TENTANG RENCANA AKSI NASIONAL PENCEGAHAN DAN PEMBERANTASAN PENYALAHGUNAAN DAN PEREDARAN GELAP NARKOTIKA DAN PREKURSOR NARKOTIKA: Deny G., Sartika Dewi, Dicky I.

di lakukan sebagai pendukung dari program pemerintah, diantaranya adalah sebagai berikut :

1. Memberikan informasi yang seluasluasnya terkait keberadaan Klinik Pertama di BNN Kabupaten Karawang baik melalui media sosial maupun media cetak. Bahkan informasi ini di berikan pada saat adanya kegiatan penyuluhan dan sosialisasi program P4GN kepada seluruh element masyarakat lingkungan daerah Kabupaten Karawang. Hal ini tentunya bertujuan agar masyarakat Kabupaten Karawang dapat mengetahui dan dapat dijadikan sebagai rujukan apabila ada anggota keluarga masyarakat yang menjadi korban penyalahgunaan narkotika untuk dilakukan rehabilitasi oleh BNN Kabupaten Karawang dan pihak terkait.

2. Untuk mengatasi wilayah cangkupan yang luas maka BNN Kabupaten Karawang akan membentuk Satuan Tugas (SATGAS) di seluruh wilayah kecamatan yang ada di wilayah Kabupaten Karawang. Sehingga, kinerja dari BNN Kabupaten
Karawang tidak menjadi terhambat akibat dari luasnya wilayah pemantauan dan pengawasan terhadap kegiatan penyalahgunaan dan peredaran gelap narkotika dan prekursor narkotika di seluruh wilayah Kabupaten Karawang.

3. Mengajak masyarakat khususnya masyarakat Kabupaten Karawang untuk bersama-sama turut ikut serta dalam memberantas narkoba, hal ini didukung dengan menanamkan pengetahuan, pemahaman akan bahaya narkoba bila digunakan pada masyarakat. Atau sebagai agen pengawasan langsung.

4. Membentuk relawan Anti Narkoba di seluruh wilayah kecamata Kabupaten Karawang yang mana BNN Kabupaten Karawang memfasilitasi pelatihan terkait dengan rehabilitasi medis rawat jalan, agar nantinya satgas ini mampun membantu tenaga konselor dalam melakukan pengawasan berkala terhadap para residen. Pada dasarnya kita mengetahui bahwa Rehabilitasi medis rawat jalan ini berbeda dengan rehabilitasi rawat inap yang 
PERAN BADAN NARKOTIKA NASIONAL KABUPATEN KARAWANG DALAM PROGRAM (P4GN) BERDASARKAN INSTRUKSI PRESIDEN REPUBLIK INDONESIA NOMOR 6 TAHUN 2018 TENTANG RENCANA AKSI NASIONAL PENCEGAHAN DAN PEMBERANTASAN PENYALAHGUNAAN DAN PEREDARAN GELAP NARKOTIKA DAN PREKURSOR NARKOTIKA: Deny G., Sartika Dewi, Dicky I.

mana rehabilitasi rawat inap ini lebih banyak aktivitas yang dilakukan pada lembaga rehabilitasi, kemudian juga didalam rawat inap tersebut para residen bisa dipantau dengan mudah oleh para konselor maka dari itu pengawasan dalam rawat inap ini sangat intens sekali. Kemudian dengan adanya relawan tersebut, diharapkan mampu secara efektif melakukan rehabilitasi medis rawat jalan dengan program home visit, yang mana home visit ini adalah para kornselor mengunjungi rumah mereka satu persatu guna melihat perkembangan dari para residen.

5. Bekerjasama dengan seluruh instansi terkait yang berada dilingkungan daerah Kabupaten Karawang yang bertujuan untuk membantu pelakasanaan rehabilitasi medis rawat jalan di Badan Narkotika Nasional Kabupaten Karawang. Kerjasama ini yaitu kerjasama dalam bentuk penanganan pada saat melakukan pelaksanaan Rehabilitasi medis rawat jalan, jadi bukan hanya sekedar kerjasama dalam hal $\mathrm{BNN}$
Kabupaten

Karawang merekomendasikan residennya kesana, akan tetapi juga membantu dan turut serta dalam melakukan pelaksanaan narkoba. Kerjasama ini dirasa sangat penting sekali karena mengingat tenaga Medis yang terbatas. Maka dari itu dengan adanya kerjasama antar instansi ini mampu membuat pelaksanaan rehabilitasi medis rawat jalan di BNN Kabupaten Karawang. beberpa yang telah melakukan kerjasama dengan BNN Kabupaten Karawang dalam hal rehabilitasi rawat jalan dan rawat inap adalah Lembaga Pantura Plus, Rumah Sakit Islam Karawang, Rumah Sakit Izza Karawang,Puskesmas Karawang Kota dan Rumah Sakit Citra Sari Husada.

6. Mengadakan Program Desa Bersinar yakni salah satu program BNN untuk memberantas penyalahgunaan narkoba yang direncanankan sejak beberapa waktu belakangan adalah Perencanaan Desa Bersih Narkoba atau Desa Bersinar di seluruh daerah di Indonesia. Program Desa 
PERAN BADAN NARKOTIKA NASIONAL KABUPATEN KARAWANG DALAM PROGRAM (P4GN) BERDASARKAN INSTRUKSI PRESIDEN REPUBLIK INDONESIA NOMOR 6 TAHUN 2018 TENTANG RENCANA AKSI NASIONAL PENCEGAHAN DAN PEMBERANTASAN PENYALAHGUNAAN DAN PEREDARAN GELAP NARKOTIKA DAN PREKURSOR NARKOTIKA: Deny G., Sartika Dewi, Dicky I.

Bersinar ini digulirkan oleh BNN untuk mengedepankan peran pemerintah daerah di seluruh Indonesia sebagai garda terdepan pemberantasan narkoba, selain program ini dilaksanakan pula karena keterbatasan dana yang dimiliki BNN untuk memberantas penyalahgunaan narkoba. Jadi sejarahnya program Desa Bersinar ini hasil dari kerjasama BNN dengan Kementerian Desa, Pembangunan Daerah Tertinggal, dan Transmigrasi yang bersepakat untuk menerapkan desa yang bebas dari penyalahgunaan narkoba.

Selanjutnya, Berdasarkan hasil wawancara secara langsung dengan salah satu personil pencegahan dan pemeberdayaan masyarakat Badan Narkotika Nasional Kabupaten Karawang terhadap startegi BNN Kabupaten Karawang dala upaya penanggulangan terhadap peredaran gelap dan penyalahgunaan narkoba adalah sebagai berikut :

1. Strategi Pengurangan Permintaan (Demand Reduction) Narkoba Strategi pengurangan permintaan meliputi pencegahan penyalahgunaan narkoba. Upaya ini meliputi:

a. Primer atau pencegahan dini. Yaitu ditujukkan kepada individu, keluarga atau komunitas dan masyarakat yang belum tersentuh oleh permasalahan penyalahgunaan dan peredaran gelap narkoba, dengan tujuan membuat individu, keluarga, dan kelompok untuk menolak dan melawan narkoba.

b. Pencegahan sekunder atau pencegahan kerawanan. Yaitu ditujukan kepada kelompok atau komunitas yang rawan terhadap penyalahgunaan narkoba. Pencegahan ini dilakukan melalui jalur pendidikan, konseling, dan pelatihan agar mereka berhenti, kemudian melakukan kegiatan positif dan menjaga agar mereka tetap lebih mengutamakan Kesehatan.

c. Pencegahan tertier Yaitu pencegahan terhadap para pengguna atau pecandu kambuhan yang telah 
PERAN BADAN NARKOTIKA NASIONAL KABUPATEN KARAWANG DALAM PROGRAM (P4GN) BERDASARKAN INSTRUKSI PRESIDEN REPUBLIK INDONESIA NOMOR 6 TAHUN 2018 TENTANG RENCANA AKSI NASIONAL PENCEGAHAN DAN PEMBERANTASAN PENYALAHGUNAAN DAN PEREDARAN GELAP NARKOTIKA DAN PREKURSOR NARKOTIKA: Deny G., Sartika Dewi, Dicky I.

mengikuti program teraphi dan rehabilitas, agar tidak kambuh lagi.

2. Pengawasan Sediaan (Supply Control) Narkoba

a. Pengawasan Jalur Legal Narkoba Narkoba dan prekusor untuk keperluan medis dan ilmu pengetahuan serta untuk keperluan industri diawasi oleh pemerintah. Pengawasan jalur legal ini meliputi pengawasan penanaman, produksi, importasi, eksportasi, transportasi penggudangan, distribusi dan penyampaian oleh instansi terkait, dalam hal ini departemen kehutanan.

b. Pengawasan Jalur Ilegal Narkoba Pengawasan jalur ilegal narkoba meliputi pencegahan di darat, di laut dan di udara. Badan narkotika nasional telah membentuk Airport dan seaport interdiction task force (satuan tugas pencegahan pada kawasan pelabuhan udara dan pelabuhan laut)
Berdasarkan hasil analisis dari peneliti terkait dengan kendala yang dihadapi oleh BNN Kabupaten Karawang dalam proses realisasi program-program pemerintah tersebut dalam Pencegahan Pemberantasan Penyalahgunaan dan Peredaran Gelap Narkotika dan Prekursor Narkotika, terutama adalah terkait dengan anggaran yang khusus di anggarkan untuk operasional yang masih terbatas. Sebagaimana hal tersebut, tentunya ini akan mempengaruhi beberapa aspek-aspek dalam peningkatan kualitas dan kuantitas dalam Badan Organisasi tersebut.

Personil BNN Kabupaten Karawang Yang Terbatas, hal ini tentunya pembagian personil didasarkan pada regulasi yang mengatur demikian. Tetapi dalam kuantitas SDM BNN Karawang sendiri tidak diatur secara spesifik terhadap jumlah konkretnya. Tetapi dalam hal keterbatasan ini, seluurhnya sudah pasti akan dikembalikan kepada anggaran dari pemerintah yang dikhususkan untuk operasional BNN itu sendiri. Semakin banyak personil, semakin besar pula anggaran yang harus pemerintah keluarkan untuk biaya operasionalnya, sementara dalam hal realisasi tugas dan fungsi harus optimal mengingat, program P4GN ni merupakan urgensi pemerintah 
PERAN BADAN NARKOTIKA NASIONAL KABUPATEN KARAWANG DALAM PROGRAM (P4GN) BERDASARKAN INSTRUKSI PRESIDEN REPUBLIK INDONESIA NOMOR 6 TAHUN 2018 TENTANG RENCANA AKSI NASIONAL PENCEGAHAN DAN PEMBERANTASAN PENYALAHGUNAAN DAN PEREDARAN GELAP NARKOTIKA DAN PREKURSOR NARKOTIKA: Deny G., Sartika Dewi, Dicky I.

terhadap kasus penyalahgunaan narkotika dan prekursor narkotika.

Dari terbatasnya personel, sudah pasti akan mempengaruhi kepada daya jangkau pengawasan BNN Karawang terhadap daerah-daerah di Kabupaten Karawang yang pada akhirnya prioritas pengawasan hanya untuk daerah-daerah rawan peredaran gelap narkotika saja. Fungsi anggaran juga akan mempengaruhi ketersediaan sarana dan prasarana yang dimiliki oleh BNN Karawang untuk dapat mempermudah kinerja dalam merelisasikan fungsi dan perannya dalam hal pengawasan peredaran gelap narkotika. Yang mana berdasarkan pandangan dari penulis, seharusnya antara sarana untuk mempermudah kinerja suatu organisasi tidak tepat jika harus seimbang dengan jumlah SDM dalam organisasi ketika yang menjadi soal adalah efisiensi anggaran. Ini pula berlaku dalam pembentukan agen anti narkoba yang semaksimal mungkin dapat di bentuk di masing-masing wilayah Desa yang ada di Kabupaten Karawang.

Hasil analisis selanjutnya penulis dapat menjelaskan bahwa, tingkat kesadran untuk dapat memanfaatkan teknologi dunia maya, di tuguh BNN Karawang ini sendiri masih belum optimal, dan strategi dalam hal mensosialisasikan kepada masyarakat perihal P4GN ini pun masih belum optimal. Dalam hal sosialisasi, BNN Karawang seharusnya dapat memanfaatkan anggaran dan tentunya media dunia maya agar seluruh masayarakat dapat menerima sosialisasi dengan baik. Seperti misalnya khusus untuk masyarakat yang melek teknologi yang ratarata adalah masayarakat perkotaan, sosialisasi dapat dilakukan dengan memanfaatkan dunia maya dan atu sosial media, sedangkan masayrakat di pedesaan di datangi langsung secara tatap muka yang tentunya inilah yang memakai anggaran tersebut. sehingga dapat disimpulkan bahwa, BNN Karawang terkait dengan hambatan dalam proses realisasi funsgi dan perannya di dalam realisasi Program P4GN ini disebabkan karena anggaran terbatas yang berdampak pada kesadaran SDM di dalam BNN itu sendiri..

\section{KESIMPULAN}

Badan Narkotika Nasional Kabupaten Karawang yakni seksi pencegahan dan pemberdayaan masyarakat, seksi rehabilitasi dan seksi pemberantasan dalam melaksanakan dan mengimplementasikan Instruksi Presiden 
PERAN BADAN NARKOTIKA NASIONAL KABUPATEN KARAWANG DALAM PROGRAM (P4GN) BERDASARKAN INSTRUKSI PRESIDEN REPUBLIK INDONESIA NOMOR 6 TAHUN 2018 TENTANG RENCANA AKSI NASIONAL PENCEGAHAN DAN PEMBERANTASAN PENYALAHGUNAAN DAN PEREDARAN GELAP NARKOTIKA DAN PREKURSOR NARKOTIKA: Deny G., Sartika Dewi, Dicky I.

Nomor 6 Tahun 2018 tentang Rencana Aksi

Nasional Pencegahan Dan Pemberantasan Penyalahgunaan Dan Peredaran Gelap Narkotika Dan Prekursor Narkotika telah sesuai dengan kegiatan yang telah direalisasikan selama periode tahun 2018 hingga periode tahun 2019. Akan tetapi dalam melaksanakan aksinya tersebut, BNNK Karawang memiliki keterbatasan jangkauan wilayah untuk adanya monitoring setiap saat dan setiap waktu terhadap kegiatan penyalahgunaan dan pengedaran gelap narkotika dan prekursor narkotika di Kabupaten Karawang.

\section{DAFTAR PUSTAKA}

\section{A. BUKU-BUKU}

Achmad Ali, Menguak Tabir Hukum, Ghalia Indonesia, Bogor, 2008.

Anton M. Mulyono, Kamus Besar Bahasa Indonesia, Balai Pustaka, Jakarta, 1988.

Badan Narkotika Nasional, Republik Indonesia. Kamus Narkoba Istilah- istilah Narkoba dan Bahaya Penyalahgunaannya, Jakarta, 2007

Burhan Mustofa, Metode Penelitian Hukum, Rineka Cipta, Jakarta, 2004.

F Asya, Narkotika dan Psikotropika, Asa Mandiri, Jakarta, 2009.

Hari Sasangka, Narkotika dan Psikotropika dalam Hukum Pidana, Mandar Maju, Bandung, 2003.
Makaraou. Moh. Taufik, Tindak Pidana Narkotika, Jakarta : Ghalia Indonesia. 2003

Sholehuddin, M., Sistem Sanksi Dalam Hukum Pidana Ide Dasar Double track System dan Implementasinya, Raja Grafindo persada, Jakarta, 2003

Soerjono Soekanto, Sosiologi suatu Pengantar, P.T.Raja Grafindo, Jakarta, 2007.

Yusuf Apandi, Katakan tidak pada narkoba, Simbiosa Rekatama Mebia, Bandung, 2010

\section{B. PERATURAN PERUNDANG- UNDANGAN}

Undang-Undang Dasar Negara Republik Indonesia Tahun 1945

Undang-Undang Nomor 35 Tahun 2009 tentang Narkotika

Peraturan Menteri Dalam Negeri Republik Indonesia Nomor 12 Tahun 2019 tentang Fasilitasi Pencegahan dan Pemberantasan Penyalahgunaan dan Peredaran Gelap Narkotika dan Prekursor Narkotika.

Peraturan Presiden Republik Indonesia Nomor 23 Tahun 2010 Tentang Badan Narkotika Nasional

Intruksi Presiden Republik Indonesia Nomor 6 Tahun 2018 tentang Rencana Aksi Nasional Pencegahan dan Pemberantasan Penyalahgunaan dan Peredaran Gelap Narkotika dan Prekursor Narkotika (P4GN) Tahun 20182019.

Peraturan Daerah Nomor 9 Tahun 2019 Tentang Fasilitasi Pencegahan dan Pemberantasan Penyalahgunaan dan Peredaran Gelap Narkotika (P4GN) 
PERAN BADAN NARKOTIKA NASIONAL KABUPATEN KARAWANG DALAM PROGRAM (P4GN) BERDASARKAN INSTRUKSI PRESIDEN REPUBLIK INDONESIA NOMOR 6 TAHUN 2018 TENTANG RENCANA AKSI NASIONAL PENCEGAHAN DAN PEMBERANTASAN PENYALAHGUNAAN DAN PEREDARAN GELAP NARKOTIKA DAN PREKURSOR NARKOTIKA: Deny G., Sartika Dewi, Dicky I.

$$
\begin{array}{rr}
\text { Peraturan Kepala Badan } & \text { Narkotika } \\
\text { Nasional } & \text { Nomor } \\
\text { PER/4/V/2010/BNN } & \text { Tentang } \\
\text { Organisasi Dan Tata Kerja Badan } \\
\text { Narkotika Nasional Provinsi Dan } \\
\text { Badan Narkotika } & \text { Nasional } \\
\text { Kabupaten/Kota } &
\end{array}
$$

\section{SUMBER LAIN}

Heriady Willy, Berantas Narkotika Tak Cukup Hanya Bicara-(Tanya Jawaban dan Opini), Universitas Islam Indonesia, Yogyakarta, 2005.

Ringkasan Eksekutif Survei Nasional Perkembangan Penyalahgunaan dan Peredaran Gelap Narkoba Pada KelompokPelajar dan Mahasiswa di 16 Provinsi di Indonesia Tahun 2011. Diakses melalui

http://bnn.go.id/portal/_uploads/ post $/ 2012 / 05 / 29 / 2012052914503$

2- 10261.pdf. Pada tanggal 19 September 2020. Pukul 13.15 WIB.

\footnotetext{
http://pn-

karanganyar.go.id/main/index.ph $\mathrm{p} /$ berita/arikel/997-pencegahanpenyalahgunaan-narkotika diakses pada tanggal 19 September 2020,

Jenis-jenis Narkotika Yang Umum di Masyarakat, www.bnn.co.id, diakses pada 03 Mei 2020 Pukul $21.00 \mathrm{wib}$

Direktorat Diseminasi Informasi, Deputi Bidang Pencegahan Badan Narkotika Nasional Republik Indonesia, Buku Panduan Pencegahan Penyalahgunaan Narkoba Sejak Dini, Jakarta, 2012.
}

BNN, Peran Badan Narkotika Nasional (BNN) Dalam Penanggulangan Narkotika di Kota Samarinda, Jurnal Ilmu Pemeritahan, Volume 5 Nomor 3, September 2015

Halimah Tusa'diah Nst, Skripsi : Peranan Badan Narkotika Nasional (BNN) Dalam Penanggulangan Tindak Pidana Narkotika Menurut UndangUndang Nomor 35 Tahun 2009 Tentang Narkotika, Universitas Sumatera Utara, Medan, 2006.

Laporan Tahunan Badan Narkotika Nasional Kabupaten Karawang Perode 2018-2019 